\title{
A consciência consciente - Autonomia e heteronomia
}

\section{Maria Luisa Couto Soares}

Num artigo publicado na Phainomenon', João Paisana refere-se ao problema do conhecimento estabelecendo a oposição entre uma teoria autónoma e uma teoria heterónoma: em Aristóteles, o conhecido funda-se na substância, é em primeiro lugar uma determinação desta e só potencialmente cognoscível. Por isso, afirma, "o conhecimento não possui autonomia ontológica, não possui 'suficiência de ser'". Pelo contrário, para Descartes, o conhecimento é antes de mais uma determinação do ego, do sujeito cognoscente. Caracterizado como pensamento e sendo o pensamento o atributo essencial de uma substância que é o ego, o conhecimento conduz-nos directamente ao ego, e só indirectamente a uma possível realidade exterior. Por isso pode falar-se do âmbito do conhecimento como de um dominio autónomo, fundado exclusivamente no âmbito da subjectividade ${ }^{2}$. A consequência a tirar destes dois modos opostos de enquadrar o conhecimento conhecimento-do-objecto, conhecimento dirigido para outro que não a própria consciência, versus conhecimento-do-eu, auto-conhecimento primeiro e absolutoé-nos apresentada sob a forma de um dilema: ou o conhecimento é considerado como conhecimento-do-objecto, mantendo assim a sua dimensão cognitiva, mas perdendo a autonomia, ou o conhecimento é considerado como um atributo do ego, mantendo a autonomia, mas perdendo a sua dimensão cognitiva (só indirecta e obliquamente será conhecimento-de-objecto) ${ }^{3}$.

Autonomia versus heteronomia, ou tautologia versus heterologia do conhecimento, traduz em forma dilemática o problema de reconciliar a dimensão essencialmente intencional do conhecimento e de toda a consciência, como conhecimento ou consciência-de-objecto, com a dimensão reflexiva como conhecimento ou consciência de si mesmo, auto-conhecimento ou auto-consciência. Com efeito, a filosofia moderna herdou esta dissociação entre intencionalidade e reflexão, entre conhecimento-do-mundo e conhecimento-de-si, tratando destas duas dimensões de modo disjuntivo, vendo geralmente uma incompatibilidade e irreconciliação entre as duas direcções da própria consciência. No primeiro caso na consciência-de-objecto - estamos perante uma forma de conhecimento incerta, duvidosa, da qual é excluída a evidência e a imediatez, tornando o acesso ao mundo externo um problema de difícil solução. No segundo caso - a consciência-de-si o auto-conhecimento revela-se como absolutamente evidente, imediato, inques-

\footnotetext{
1 "A dúvida de Descartes e a substância aristotélica", Phainomenon, n. 2, Primavera 200I, pp. 87-97.

2 Cfr. ibidem, pp. 93-94.

3 Cfr. ibidem, p. 95.
} 
tionável. Entre a incerteza e a dúvida que perpassa no conhecimento-do-objecto, na consciência-do-mundo, e a evidência do auto-conhecimento, naturalmente a tendência dominante foi a de privilegiar esta segunda dimensão, deixando a dimensão intencional na tonalidade nebulosa de uma atitude céptica. Esta mesma dualidade revela-se na disjunção, que percorre quase toda a modernidade, entre verdade e sentido. Esta separação constitui mesmo uma das marcas mais relevantes do estilo moderno de pensar e são raros os filósofos que não acusam esta cicatriz provocada pela brecha aberta entre a dimensão veritativa, entre o verdadeiro ou acesso cognitivo ao mundo real e a dimensão de sentido, ou o dar-se-nos de um certo modo, o apresentar-se à consciência segundo uma determinada perspectiva; as teorias da verdade que se reclamam em exclusivo da primeira dimensão, entendendo por verdade uma correspondência entre o conhecido e o real em si mesmo considerado, revelam rapidamente as dificuldades em apresentar uma explicação da verdade que prescinda da dimensão subjectiva, ou da dimensão reflexiva. Entre o objecto conhecido enquanto conhecido e o objecto em si mesmo considerado, não há forma de estabelecer uma mediação e todas as tentativas de explicar a verdade em termos de correspondência falham pela raiz. Por outro lado, as tentativas de reintegrar o sentido, entendendo a verdade como coerência interna entre os conhecimentos e crenças, ou as versões pragmatistas, revelam-se insatisfatórias para apreender uma noção de verdade que seja epistemicamente fecunda para dar conta do nosso modo de conhecer.

A questão poderia reformular-se: é incompatível a consciência-do-mundo, como consciência-de-objecto, numa direcção referencial que a transporta para além de si mesma, com a consciência-de-si, o auto-conhecimento imediato do próprio eu, indubitável e certo, evidente e soberano? Será possível reconciliar estas duas dimensões - a autonómica, a posse directa do próprio sujeito e a heteronómica, a direccionalidade ou referência a "algo" que está para além do próprio conhecimento enquanto fenómeno da consciência? Pode dar-se uma forma de consciência-de-objecto que seja simultaneamente e por definição sempre e também consciência-de-si? Não poderá dar-se uma forma de "consciência consciente", na qual compareçam em simultâneo o "objecto da consciência", ou em sentido lato, "o mundo da consciência", e a própria "consciência do mundo"?

É deste problema que nos propomos ocupar, revisitando Brentano e a sua noção de percepção interna, ou consciência concomitante, uma dimensão da consciência indissociável da outra dimensão - a dimensão intencional.

É bem conhecida a tese de Brentano sobre a intencionalidade de todos os fenómenos psíquicos, de toda a consciência, e a passagem emblemática da Psychology from an Empirical Standpoint que a enuncia: "Todos os fenómenos mentais se caracterizam pelo que os Escolásticos da Idade Média chamavam a inexistência intencional ou mental de um objecto, e que nós poderíamos chamar, embora não totalmente desprovido de ambiguidade, de referência a um conteúdo, direcção a um objecto (que não deve ser entendido como uma coisa), ou objectividade imanente. Todo o fenómeno mental inclui algo como objecto em si mesmo, embora não o façam todos do mesmo modo. Na representação, algo é representado, no juizo algo é afirmado ou negado, no amor, amado, no ódio odiado, no desejo desejado, etc." ${ }^{\prime 4}$.

4 Psychology from an empirical Stampoint, ed. Linda L. McAlister, Routledge \& Kegan Paul, London, 1995 p. 88. 
A relação intencional traduz a direccionalidade a um objecto, ou o que em língua inglesa se designa latamente por aboutness e corresponde, portanto, à dimensão "heteronómica" da consciência. A consciência dirige-se para algo, versa sobre algo, tem algo como seu objecto. Qual o estatuto deste objecto intencional no contexto do pensamento de Brentano, como interpretar as expressões um tanto equívocas que ocorrem na passagem supra-citada, como "inexistência intencional ou mental de um objecto", "referência a um conteúdo", "direcção a um objecto" ou "objectividade imanente" - são questões que foram longamente debatidas e exploradas tanto pelos discípulos imediatos de Brentano como pelos vários intérpretes e estudiosos do seu pensamento. Não nos ocuparemos aqui desta problemática, fundamental para entender a noção de intencional em Brentano, mas centrar-nos-emos na segunda relação que, juntamente com esta primeira, caracteriza e define toda a consciência. Esta segunda relação é a que todo o acto mental tem consigo mesmo. "Toda a consciência, seja qual for o objecto para o qual se dirige primariamente, está concomitantemente dirigida para si mesma (geht nebenher auf sich selbst). Na presentação (im Vorstellen) da cor, simultaneamente dá-se portanto uma presentação desta presentação. Aristóteles já enfatiza que o fenómeno psíquico contém a consciência de si mesmo"”.

Não há consciência sem intencionalidade, sem essa direccionalidade para algo como seu objecto primário, mas simultaneamente todo o acto consciente tem-se a si mesmo como objecto. Esta dupla relação - da consciência ao objecto e, concomitantemente, a si mesma - constitui parte essencial da natureza de todo o acto psíquico ${ }^{6}$. Isto significa que, para Brentano, não há actos psíquicos inconscientes. Se se trata de actos psíquicos, são, pela sua própria natureza objecto da própria consciência. Já na Psychology from an Empirical Standpoint, Brentano argumentara detalhadamente contra a hipótese de actos inconscientes, parả concluir que todos os fenómenos psíquicos são objecto da percepção interna, são essencialmente conscientes. Discute vários tipos de argumentos ou "vias" a favor de fenómenos psíquicos inconscientes: é o quarto argumento que tem mais relevância para se captar o que entende Brentano por percepção interna. Trata-se de provar que, se admitirmos que todo o fenómeno psíquico é objecto de um fenómeno psíquico, este segundo fenómenos será também objecto de um terceiro fenómeno psíquico, e assim num infinito regresso, desencadeando uma complicação infinita, impossível à partida e contrária à própria experiência. $\mathrm{O}$ argumento é forte, e Brentano dedica-lhe particular atenção, porque lhe vai proporcionar uma ocasião para formular explicitamente a sua noção de percepção interna. Com efeito, tomando por exemplo a presentação de um som, teremos uma presentação da presentação deste som em simultâneo. Duas presentações. Se chamarmos à presentação do som "audição" teremos, para além desta presentação do som, uma presentação da "audição", tão diferente da própria audição como esta é diferente do som. Mas, se todo o fenómeno mental deve ser acompanhado de consciência, a presentação da "audição" do som, também o deverá ser por sua vez e, consequentemente, deverá dar-se também uma presentação desta presentação; esta terceira presentação não pode ainda ser a última, pois se é também consciente, ela própria deverá também ser "presentada" à consciência. A série torna-se portanto infinita, a menos que termine com uma presentação inconsciente. Segue-se que negar a existência de

5 Descritive Psychology, ed. e trad. de Benito Müller, Routledge \& Kegan Paul, London, 1995 , p. 25.

6 Cfr. ibidem, p. 26. 
fenómenos mentais inconscientes, levará a ter de admitir um número infinito de actividades mentais no simples acto de ouvir ${ }^{7}$. A hipótese é absurda. Como é que Brentano insiste na rejeição de actos psíquicos inconscientes sem cair neste infinito regresso e infinita complicação de fenómenos psíquicos na mais simples percepção de um som?

Brentano entende que no fenómeno psíquico mais simples, há um só acto com dois objectos: o objecto para o qual se dirige primeiramente a consciência (consciência-de-objecto) e um segundo objecto constituído pelo próprio acto da consciência (consciência de si mesma). Admite-se, portanto, em toda a vida psíquica uma conexão íntima, imediata entre o princípio da intencionalidade e a reflexão deste tipo de consciência intencional. Para qualquer acto de consciência é tão fundamental que este consista numa relação intencional (que seja consciência-de-objecto), como a auto-presença do acto à própria consciência; esta presença entende-se em termos de objecto não já primário, mas secundário. No caso de uma percepção auditiva, Brentano designará "o som, o objecto primário e a própria audição, objecto secundário"8. Deste modo, qualquer manifestação psíquica se nos apresentará com esta dupla relação, pela qual somos conscientes por uma presença dupla, que se traduz numa dupla objectualidade: o termo da intencionalidade do acto e o acto propriamente dito do qual temos consciência. Brentano não distingue entre uma presença temática e uma espécie de presença atemática, ou pré-objectual, mas toda a presença é objectiva. Toda a captação intencional de "um algo" é acompanhada por uma captação reflexiva, um conhecimento desse conhecimento, que é o objecto secundário. Não se trata, porém de um segundo acto, de uma segunda representação que tem por objecto a primeira: trata-se de um só acto, que funde na sua unidade incindível, dois objectos, de tal modo que não é possível falar de intencionalidade sem reflexão. Brentano insiste na unidade do acto, apesar da duplicidade de objectos: "A presentação do som e a presentação da presentação do som constituem um único fenómeno mental: é só pela consideração deste fenómeno nas suas relações com dois objectos diferentes, um dos quais é um fenómeno físico e o outro um fenómeno mental, que o dividimos conceptualmente em duas presentações. No mesmo fenómeno mental no qual o som se torna presente às nossas mentes, apreendemos simultaneamente o próprio fenómeno mental. Mais ainda, apreendemo-lo de acordo com a sua natureza dual na medida em que ele tem o som como seu conteúdo, e na medida em que se tem a si mesmo como conteúdo ao mesmo tempo"9.

É portanto a mesma consciência do objecto que, num acto único e simples, se sabe em conjunto a si mesma, sem necessidade de se pôr como um segundo saber que se acrescenta ao primeiro. Sendo a consciência sempre auto-consciência, a circularidade da auto-consciência exclui o reenvio ao infinito. A noção de consciência consciente, tal como é tematizada por Brentano, aponta para uma integração da heteronomia e autonomia da consciência num acto único, admitindo no acto cognitivo de forma simultânea não só a referência intencional a algo distinto de si (heteronomia, ou heterologia), mas também a referência a si próprio (autonomia ou tautologia do conhecimento). Para evitar os inconvenientes da terminologia "objectivista", talvez fosse mais adequado falar aqui de uma presença "a-temática" do acto de consciência, ou de uma espécie de pré-objectualidade, entendida não como uma espécie de objecto prévio, mas como algo prévio à própria objectualidade,

Cfr. Psychology from an empirical Standpoint, p. 121-122.

Cfr. Psychology, 128.

9 Psychology, p. 127. 
se bem que exercido em simultâneo com a presença do objecto. Esta auto-presença ou auto-presentação da consciência a si mesma traduz bem a impossibilidade de pôr entre parêntesis a dimensão subjectiva como acesso perspectivista e constitui uma das teses fundamentais de Brentano, que Chisholm designou pela primazia do pessoal.

Mas esta primazia do pessoal vai levar Brentano a consequências excessivas. Todo o acto psíquico é, portanto, acompanhado de uma consciência correlativa ou concomitante, toda a consciência é auto-consciência. Qual a natureza desta consciência? Brentano afirma reiteradamente que todo o fenómeno psíquico é objecto de um conhecimento concomitante, conhecimento este que pertence ao mesmo acto psíquico, não se tratando de modo algum de um segundo acto que sobrevém ao primeiro. É precisamente esta fusão, num só e mesmo acto, da consciência-de-objecto e da consciência-da-consciência que funda a infalibilidade e evidência da percepção interna: pela percepção interna, imediatamente unida a qualquer acto de percepção, desejo, emoção, crença, etc., sabemos infalivelmente que pensamos, que desejamos, que percepcionamos, que sentimos, etc. Esta infalibilidade e absoluta evidência da percepção interna não pode ser objecto de prova ou demonstração, precisamente porque possui uma evidência imediata. Não carece de prova, e se duvidássemos deste fundamento último do conhecimento, não encontraríamos outro sobre o qual construir o edifício do saber. Não há qualquer necessidade de justificar a confiança atribuída à percepção interna. O que é necessário, é estabelecer uma teoria que se possa conciliar com a sua evidência imediata. E essa teoria seria inviável se considerássemos a percepção interna e a percepção do objecto dois actos psíquicos diferentes, sendo um o efeito do outro. Sem esta unidade real, esta ligação particularmente íntima entre o acto psíquico e a representação que o acompanha, entre este mesmo acto e a percepção interna, a evidência desta última seria impossível ${ }^{10}$.

Se, pela percepção interna, conhecemos imediatamente e com total evidência todo e qualquer fenómeno psíquico, a natureza deste conhecimento evidente só pode ser a de um juízo. E aqui surge uma outra difieuldade: o juízo é um aeto psíquieo de uma natureza diferente da presentação. Portanto, afirmar que todo o fenómeno psíquico é acompanhado sempre por um conhecimento que o tem por objecto, por um juízo correlativo, não conduzirá de novo à infinita complicação de actos psíquicos, a um infinito regresso? Brentano pensa que não, se se tem em conta a sua concepção de juízo que se distancia muito das concepções tradicionais e correntes. De acordo com as teorias do juízo correntes, este estabelece uma conexão entre uma pluralidade de conceitos e, particularmente, o juízo de existência acrescenta o conceito de existência a algum outro conceito que ocorre como sujeito do referido juízo. De acordo com esta concepção, qualquer sensação seria acompanhada por uma presentação do respectivo acto, e também em simultâneo, por uma percepção deste acto, sendo esta última um conhecimento da existência do acto, ou um juízo que liga o conceito de existência como predicado ao fenómeno mental como sujeito. Esta formulação é obviamente impossível, e fomentaria decerto uma crescente complexidade de actos e fenómenos psíquicos; é evidente que este juízo, sendo um outro acto psíquico, teria que ser, por sua vez, acompanhado por uma presentação do mesmo juízo e assim ad infinitum. Brentano rejeita esta concepção e as consequências excessivas que implicaria, com a sua própria teoria 
do juízo: no seu entender, não é, de modo algum, essencial à natureza do juízo a composição de sujeito e predicado. Concretamente este juízo da percepção interna não consiste na conexão de um acto mental como sujeito com a existência como predicado: julgar, segundo Brentano, consiste simplesmente em afirmar-aceitar o fenómeno mental presente à consciência. Trata-se de uma espécie de juízo tạ́cito, de uma simples e mera aceitação-afirmação, sem composição ou conexão entre sujeito e predicado: o juízo correlativo da percepção interna afirma simplesmente o acto psíquico presente ${ }^{11}$.

Este conhecimento que qualquer sujeito tem de si mesmo e que se dá concomitantemente a qualquer outro acto psíquico ou mental, pelo qual sei que penso, que percepciono, que ouço, que desejo, etc., é um conhecimento imediatamente evidente, se bem que se trate de um conhecimento múltiplo. Tal como o Cogito cartesiano, inclui uma grande pluralidade de fenómenos psíquicos: vejo, ouço, duvido, estou certo, sinto prazer, desejo, quero, irrito-me, etc., tudo pertence ao mesmo pensamento, toda esta variedade de fenómenos conscientes, são, não só consciência-de-algo, mas envolvem uma consciência que o sujeito tem de si mesmo vendo, ouvindo, duvidando, desejando, etc. E todos estes fenómenos são simultaneamente conhecidos pelo sujeito e apreendidos de modo imediatamente evidente. Brentano vai mais longe: só este conhecimento-de-si é realmente evidente e duma evidência máxima a consequência a tirar será mesmo a de que não se pode admitir como imediatamente evidente nada mais que o Eu presente, e rejeitar como injustificada a crença no eu passado e na duração anterior. A evidência exclusiva

11 A modo de recapitulação, Brentano sintetiza as teses principais sobre a consciência: "Todo o acto mental é consciente. Portanto, todo o acto mental, por mais simples que seja, tem um duplo objecto, um objecto primário e um secundário. $\mathrm{O}$ acto mais simples, por exemplo o acto de ouvir, tem como objecto primário o som e como seu objecto secundário, o próprio acto, o fenómeno mental no qual se ouve o som. A consciência deste objecto secundário é tripla: envolve uma presentação desse acto, um conhecimento e um sentimento em relação ao mesmo acto. Consequentemente, todo o acto mental, por mais simples que seja, apresenta quatro aspectos diferentes sob os quais pode ser considerado. Pode ser considerado como uma presentação do seu objecto primário, quando o acto no qual percebemos um som é considerado como um acto de ouvir; no entanto, pode também ser considerado como uma presentação de si mesmo, como um conhecimento de si e como um sentimento para si mesmo. Além disso, nestes quatro aspectos, há o objecto da sua auto-presentaçã̃o, do seu auto-conhecimento, e (de algum modo) do seu auto-sentimento. Assim, sem mais complicação e multiplicação de entidades, não só é presentada a auto-presentação, o auto-conhecimento é conhecido assim como presentado, e o auto-sentimento é sentido, como conhecido e presentado" (Psychology, p. 153-154).

12 Brentano chega a formular esta tese extrema do solipsismo num texto inserido na edição francesa da Psychologie du point de vue empirique, pp. 363-364, que não consta na edição inglesa. O título é "De la Conscience sensible et noétique" - título sob o qual Kraus agrupa diversos textos de datas diferentes e que constituem o III volume da Psychology, inacabada. O I capítulo deste texto, "De la perception interne au sens étroit de conscience seconde", foi escrito para servir de introdução à Metafísica projectada por Brentano.

Num texto de 1915, "On the Evident", Brentano afirma expressamente que os nossos juízos directamente evidentes se restringem ao conhecimento do nosso próprio eu e ao presente. Nenhum momento do passado ou do futuro podem ser afirmados com a mesma evidência directa de um momento presente (The True and the Evident, trad. Chisholm, R., ed. Politzer, I. e Fischer, K. R. Routledge \& Kegan Paul, London, 1966, p. 131). 
do próprio Eu presente a si mesmo, relegando para o estatuto de mera crença provável a existência do mundo, corresponde à tese de um solipsismo do momento presente ${ }^{12}$.

A evidência imediata, indubitável pertence em exclusivo à percepção interna, de tal modo que, em boa verdade, esta é a única percepção no sentido estrito da palavra (Wahrnehmung, apreensão do verdadeiro). A percepção dos fenómenos externos, em sentido rigoroso, não é propriamente uma percepção, visto que o que se apreende é da ordem do fenoménico: a cor, o som, o calor têm apenas uma existência fenomenal e intencional; só os fenómenos psíquicos são realmente objecto de percepção, tomando o termo no seu autêntico sentido etimológico, como apreensão do verdadeiro: Brentano não pretende afirmar que as coisas exteriores sejam meras representações do sujeito, o que quer dizer simplesmente é que as qualidades sensíveis não existem verdadeira e realmente fora das sensações, embora estas nos revelem algo que existe verdadeira e realmente. Não nega a existência do mundo exterior, mas nega que o conhecimento que dele temos possua um carácter imediatamente evidente, exclusivo da percepção interna. Em relação ao mundo externo, o que dele percebemos só nos permite formular uma hipótese que apresenta uma grande probabilidade. A verdade dos fenómenos físicos é uma verdade meramente relativa.

O percurso do pensamento de Brentano vai incidindo cada vez com mais força na dimensão da evidência que só alcança a sua plena forma naqueles juízos que têm como objecto directo o próprio sujeito. Brentano explica assim a evidência como reflexão - reflexão que significa uma identidade do sujeito consigo mesmo, sem que haja outro termo, qualquer outra realidade fora do espírito, extra-mental. É natural que a orientação do pensamento de Brentano no sentido de uma progressiva concentração na dimensão puramente reflexiva da consciência, o tenha levado a uma reformulação da natureza do intencional, inicialmente definida em termos de relação. Se o acto psíquico só se pode ter a si mesmo como objecto imediato, e tudo o resto - os fenómenos externos, o mundo real - só derivada e em sentido secundário poderão ser percebidos pelo sujeito, todo o conhecimento de uma alteridade que não seja o próprio sujeito é posto em causa - nada se pode conhecer com evidência a não ser o próprio sujeito, a consciência-de-algo exige e implica primariamente uma auto-direcção da consciência para si mesma. $\mathrm{O}$ intencional passará a ser considerado, já não como algo relativo, mas como uma para-relação (etwas Relativisches), uma relação unipolar que se estabelece no sujeito e com o próprio sujeito, sempre com uma absoluta evidência. A intencionalidade como "referência-a", ou direcção-para", que desempenhara um papel decisivo na definição e caracterização dos actos psíquicos, foi perdendo o seu lugar principial e orientador, para dar lugar a outra nota, também essencial na caracterização dos mesmos actos psíquicos: o carácter reflexivo da consciência interna, que atribuía o carácter de conscientes a todos os fenómenos psíquicos. Se nos primeiros textos da Psychology, as duas dimensões - intencional e reflexiva - se encontravam num aparente equilíbrio, não há dúvida que pouco a pouco, o centro de gravidade no modo de considerar a própria consciência, vai-se deslocando visivelmente para a segunda dimensão: de início, para Brentano, toda a consciência é consciência-de-algo e, nebenbei (secundariamente) é consciência de si mesma; nas formulações posteriores toda a consciência é em primeiro lugar e fundacionalmente, consciência de si mesma, e só nebenbei é consciência-de-algo. A percepção do eu (Selbstwahrnehmung) é a única evidente, e a grande maioria dos juízos que emitimos sobre realidades externas são designados por Brentano como juízos "cegos" (blinden Urteile). 
Os resultados excessivos da orientação do pensamento de Brentano, concentrado na dimensão puramente reflexiva de um sum psíquico, abrem caminho, como o próprio Brentano o reconhece, à suspeita de um solipsismo extremo, o solipsismo do momento presente, e provocaram as naturais acusações de psicologismo. Acusações não totalmente justas, se tivermos em conta que os intentos de Brentano visavam essencialmente reconciliar as dimensões intencional e reflexiva da consciência - a heteronomia e a autonomia de todo o fenómeno psíquico. Por isso mesmo, ao rever o problema da verdade, Brentano rejeita uma teoria meramente "adequacionista" que privilegie a vertente correspondencialista em detrimento da imprescindivel vertente reflexiva. Não se pode considerar a verdade do conhecimento sem partir da própria asserção no sentido de acto psíquico, sem o reconduzir no entanto a uma redução meramente psicológica. Brentano insiste sobretudo na dimensão psíquica, ausente nas abordagens puramente lógicas das teorias do juízo, enfrentando-se com a "ontificação" dos conteúdos do juízo ou de qualquer acto intencional; contra as extrapolações de alguns dos seus discípulos mais directos que traduziram a noção um tanto ambígua de "objecto intencional" por conteúdos efectivos chegando a formulações completamente estranhas ao seu pensamento, como no caso de Meinong com a sua teoria do Objecto, Brentano não se propõe "psicologizar" qualquer acto de conhecimento, mas integrar a componente psíquica que se traduz precisamente na dimensão reflexiva, essencial para restabelecer o alcance veritativo de todo o juízo.

As posições extremas que parecem vislumbrar-se no horizonte do pensamento brentaniano - solipsismo, psicologismo - manifestam apenas a dificuldade de reconciliar estas duas dimensões do conhecimento - intencionalidade e reflexão, heteronomia e autonomia. Dificuldade agravada pelo peso da modernidade que assenta toda a sua reflexão sobre o conhecimento na disjunção destas duas dimensões. A sua reconciliação e harmonia constitui um desafio estimulante para a reformulação actual dos problemas da teoria da mente e da actividade cognitiva. 